\title{
Don't judge a fish by its fins: species delineation of Congolese Labeo (Cyprinidae).
}

Article in Zoologica Scripta · December 2016

DOI: $10.1111 /$ zsc.12203

CITATIONS

0

5 authors, including:

\section{Maarten Van Steenberge}

Royal Museum for Central Africa

24 PUBLICATIONS 112 CITATIONS

SEE PROFILE

\section{Vreven Emmanuel}

Royal Museum for Central Africa

66 PUBLICATIONS 229 CITATIONS

SEE PROFILE
READS

52
Laura Gajdzik

University of Liège

10 PUBLICATIONS 10 CITATIONS

SEE PROFILE

Some of the authors of this publication are also working on these related projects:

Towards sustainable fisheries in Lake Tanganyika through genomics, parasitology and stakeholder 


\title{
Don't judge a fish by its fins: species delineation of Congolese Labeo (Cyprinidae)
}

\author{
Maarten Van Steenberge, laura Gajdzik, Alex Chilala, Jos Snoeks \& Emmanuel Vreven
}

Submitted: 25 January 2016

Accepted: 1 July 2016

doi: $10.1111 /$ zsc. 12203

Van Steenberge, M., Gajdzik, L., Chilala, A., Snoeks, J., Vreven, E. (2016). Don't judge a fish by its fins: species delineation of Congolese Labeo (Cyprinidae). - Zoologica Scripta, 00, $1-11$.

Conspicuous characters are often useful in species identification. Yet, identification and delineation are two different processes, and such characters do not necessarily provide the best basis on which species can be delineated. This is illustrated by the case of the Labeo with papillary lips from the Congo basin. Traditionally, species delineation in this group was based on a conspicuous trait: the shape of the dorsal fin, which shows a profound degree of differentiation. Morphometric analyses were performed on 185 specimens both with and without measurements taken on this fin. The groups obtained using these two approaches were compared with those obtained through DNA barcoding. For this, 24 sequences of the standard barcoding COI gene were obtained. Species delineations based on morphological and molecular results were in agreement when the shape of the dorsal fin was ignored. This suggested that of the five nominal species known from the Congo basin, L. altivelis, L. rosae, L. lineatus, L. weeksii and L. maleboensis, only the former three remain valid. Consequently, L. weeksii was synonymised with $L$. altivelis and L. maleboensis with L. lineatus. The sole Congo basin endemic is L. lineatus as L. altivelis and L. rosae also occur in more southern basins. The use of the shape of the dorsal fin in morphological studies has previously led to overestimates of species diversity in this group. This is due to the fact that $L$. altivelis shows a remarkable amount of geographical variation for this trait. The large amount of intra- and interspecific variation in this character was caused by differential allometric growth in different parts of the dorsal fin.

Corresponding author: Maarten Van Steenberge, Royal Museum for Central Africa, Leuvensesteenweg 13, Tervuren B-3080, Belgium. E-mail: maarten.vansteenberge@bio.kuleuven.be

Maarten Van Steenberge, Ichthyology, Vertebrates Section, Royal Museum for Central Africa, Leuvensesteenweg 13, Tervuren B-3080, Belgium and Department of Biology, Laboratory of Biodiversity and Evolutionary Genomics, KU Leuven, Charles Deberiotstraat 32, Leuven B-3000, Belgium. E-mail: maarten.vansteenberge@bio.kuleuven.be

Laura Gajdzik, Laboratory of Functional and Evolutionary Morphology, AFFISH Research center, Institute of Chemistry (B6C), University of Liege, Liege B-4000, Belgium. E-mail: laura.gajdzik @ulg.ac.be

Alex Chilala, Department of Fisheries, Ministry of Agriculture and Livestock, Chilanga, Zambia. E-mail: chilalaalex@gmail.com

fos Snoeks, and Emmanuel Vreven, Ichthyology, Vertebrates Section, Royal Museum for Central Africa, Tervuren B-3080, Belgium and Laboratory of Biodiversity and Evolutionary Genomics, KU Leuven, Charles Deberiotstraat 32, Leuven B-3000, Belgium. E-mail: jos.snoeks@africamuseum.be, emmanuel.vreven@africamuseum.be

\section{Introduction}

In view of the current biodiversity crisis, the discovery and correct delineation of taxa has become more important than ever. Yet, species delineation can be a labour-intensive process that is only achieved through time-consuming taxonomic revisions. Such works are, especially in very species-rich groups, not highly validated by current methods of scientific evaluation (Löbl 2014). Besides the delineation of species, revisions should also provide the characters that can be used for identification. As species delineation and identification are two independent processes (Mayr 1982), they do not have to be based on the 
same traits. The ideal criteria for identification are easily observable conspicuous traits that do not require a certain expertise or equipment and allow for rapid identification. When such conspicuous traits are available, it is tempting to also use them for species delineation, hereby circumventing the need to perform a full-scale revision. Yet, relying solely on (a few) conspicuous characters could result in the construction of an oversimplified classification that does not reflect biological reality. Here, we present a study on the Congolese species belonging to a well-defined lineage of African Labeo Cuvier, 1816. These fishes differ largely in the shape and size of their dorsal fins. Hence, it is no surprise that their classification was largely based on this conspicuous trait. The taxonomy of this group remained, however, confusing and species identification difficult. Therefore, this group will be revised and the systematic value of the conspicuous trait, the shape of the dorsal fin, evaluated.

Labeo species are medium- to large-sized cyprinids belonging to the Afro-Asian labein lineage (Stiassny \& Getahun 2007). Over a hundred species are described from Africa and southern Asia and, in Africa, it is third most diverse cyprinid genus, after Enteromius Cope, 1867 and Labeobarbus Rüppell, 1835 (both genera were previously known as 'Barbus'; Reid 1985; Skelton et al. 1991). Labeo species are herbivores that mostly feed on the algal growth (aufwuchs) covering the substrate. Therefore, they possess morphological adaptations such as an inferior, mobile, sucker-like mouth with folded lips and a hardened edge, a very long coiled intestine and pharyngeal grinding teeth (Matthes 1963; Reid 1985; Skelton 2001). Due to the overlap of diagnostic characters, species delineation in this genus was considered difficult (Reid 1985; Lowenstein et al. 2011). This rendered any systematic study of the genus challenging (Boulenger 1903; Reid 1985; Thys van den Audenaerde 1987; Tshibwabwa 1997; Lowenstein et al. 2011). The last pan-African revision of Labeo was performed by Reid (1985), which was followed by a revision of the species occurring in the ichthyofaunal provinces of the Congo and Lower Guinea by Tshibwabwa (1997). In the latter revision, a classification and identification scheme was designed that depended heavily on two traits: the structure of the labial folds and the shape of the dorsal fin.

African Labeo possess two distinct types of lip morphologies (Matthes 1963; Reid 1985), referred to as plicate and papillate lips. The majority of the species have plicate lips, characterised by several rows of transverse plicae on the anterior edge of the upper labial fold. Species with papillate lips have several rows of globular papillae instead (Matthes 1963; Reid 1985; Tshibwabwa 1997). It had been hypothesised that these labial morphologies defined, at least for Congo and Lower
Guinea representatives, two reciprocally monophyletic groups (Tshibwabwa 1997). Molecular studies (Lowenstein et al. 2011; Yang et al. 2012) rejected this hypothesis and showed the plicate morphotype to be ancestral, confirming earlier morphological findings of Matthes (1963). The papillate group forms, at least for its Congo basin representatives, a monophylum (Lowenstein et al. 2011).

Currently, five valid species of papillate Labeo are reported from the Congo basin (Tshibwabwa 1997; Van Steenberge et al. 2014b): L. altivelis Peters, 1852, L. rosae Steindachner, 1894, L. lineatus Boulenger, 1898, L. weeksii Boulenger, 1909 and L. maleboensis Tshibwabwa, 1997. The first two species have their type localities in more southern basins (the Zambezi and the Limpopo, respectively). According to the identification key designed by Tshibwabwa (1997), the main criterion to distinguish these species is the shape of their dorsal fins: straight in L. lineatus and L. maleboensis, convex in L.altivelis, falciform in L. weeksii and concave in L. rosae. The latter species was identified as L. mesops Günther, 1868 by Tshibwabwa (1997) (Van Steenberge et al. 2014b) and the former two were said to differ in the number of vertebrae (31 in L. lineatus vs. 29-30 in L. maleboensis). Furthermore, a dark spot on the caudal peduncle was mentioned to be present in L. lineatus and L. maleboensis and absent in the other species.

In spite of multiple revisions (Reid 1985; Tshibwabwa \& Teugels 1995; Tshibwabwa 1997), taxonomic problems remained in Congolese Labeo (Van Steenberge et al. 2016) and specimens could often not be unambiguously identified (Decru et al. 2016). This is at least partially due to the fact that no quantitative differences were given between the different fin shapes. Moreover, a barcoding study of Lower Congo Labeo did not find molecular support for the specific status of L. maleboensis versus L. lineatus (Lowenstein et al. 2011). Finally, the main character used for identification of these cyprinids, the shape of the dorsal fin, was recorded to contain, at least for southern African populations of L. altivelis, a considerable amount of allometrical (Worthington 1933; Jubb 1958) and geographical (Bell-Cross 1976) variation.

In this study, Congolese representatives of papillate Labeo will be revised based on morphometric and molecular traits. For the morphological study, specimens from other basins belonging to species currently or previously listed from the Congo basin were also included. Special emphasis will be given to the shape of the dorsal fin, the conspicuous trait traditionally used for classification and identification in this group. Because this trait was only qualitatively recorded in previous revisions, we will integrate it in our analyses using a quantitative approach. This will also allow us to investigate allometric variation. Analyses will be 
performed both with and without measurements of the dorsal fin and compared with the lineages identified within the African Labeo with papillary lips, based on the mtDNA marker COI. This will allow us to quantify the effect of a single conspicuous trait on morphology-based species delineations.

\section{Materials and methods}

One hundred and eighty-four specimens belonging to six nominal species were examined (Appendix S1). Besides 163 specimens from the Congo basin, these consist of 14 L. altivelis specimens from the Zambezi and the Rio de Bons Sinais basins, five L. mesops from the Lake Malawi system, one L. rosae from the Limpopo River and one unidentified specimen from the Little Ruaha River (Rufiji basin), which will be referred to as $L$. sp. 'Ruaha'. The latter specimen was included as it represents, together with $L$. mesops, a papillate Labeo occurring in between the north-western and the south-eastern ranges of L. altivelis (Fig. S1). For the ease of interpretation by the reader, and based on preliminary analyses, specimens of $L$. weeksii and L. maleboensis were listed as L. altivelis and L. lineatus, respectively, in our analyses. Although this way of indicating the specimens is not standard practice in taxonomical studies, the reader can still verify the motivation of the synonymies: the holotype of L. maleboensis, which is the only large specimen available, has been labelled separately and the current notion of $L$. weeksii roughly corresponds with what is called the Congo population of $L$. altivelis below. As preliminary analyses revealed geographical variation in L. altivelis, three geographical groups will be studied. These will be referred to as: (i) the Congo population, containing specimens from the entire basin with the exception of (ii) the Bangweulu-Mweru population, comprising specimens from that ecoregion (Scott 2005) and (iii) the Zambezi population, which, besides specimens from the Zambezi basin, also contains those from the Rio de Bons Sinais. Except for two Lower Congo specimens (MRAC 47534-35) listed as L. altivelis by Tshibwabwa (1997), the Congo population contained only specimens previously identified as L. weeksii. However, curiously Tshibwabwa (1997) also listed one specimen (MRAC 37801) from the Bangweulu-Mweru population as L. weeksii. The majority of the specimens originate from the collections of the Royal Museum for Central Africa, Tervuren, Belgium (for collection numbers: MRAC), but specimens of the Natural History Museum, London (BMNH), the Museum für Naturkunde, Berlin (ZMB), and the Naturhistorisches Museum, Vienna (NMW), were also included. Name-bearing types were studied for all nominal species. Twenty-one measurements were taken, 19 of which were also made by
Tshibwabwa \& Teugels (1995) (Table S1). In contrast to the latter study, where the longest dorsal-fin ray was measured, two well-specified fin rays were measured: the last unbranched and the fifth branched dorsal-fin ray (LUDR, 5th BDR). Additionally, 18 meristics were counted, following Tshibwabwa \& Teugels (1995) and Tshibwabwa (1997) except that when the last dorsal- or anal-fin ray was divided at its base, it was not treated as one, but as two fin rays. Given the presence of a minute unbranched dorsal ray, which sometimes could only be visualised using $X$-rays, the simple dorsal-fin rays ( 3 or 4 ) were not counted. The presence of the precaudal spot was scored.

For 116 specimens, vertebral counts were made. These were done on $\mathrm{X}$-rays, made using the Visix equipment (Medex Loncin SA), which includes a Gem $\times 160 \mathrm{X}$-ray generator and a high-resolution digital $\mathrm{X}$-ray detector, Dereo HR1. For the type specimens of L. altivelis and L. rosae, vertebral counts were taken from Reid (1985). Since the lectotype of L. mesops is a skin, only meristics (but no vertebrae) were recorded. Gill rakers were counted for 43 specimens. The standard barcoding gene, the first subunit of cytochrome c oxidase (COI), was sequenced following Decru et al. (2016) for five L. altivelis specimens, one from the Bangweulu-Mweru and four from the Zambezi populations (GenBank accession numbers: KX245441KX245445). As the inclusion of closely related species increases the potential of DNA barcoding, our sequences were compared with those from all African papillate Labeo available on GenBank (Lowenstein et al. 2011; Yang et al. 2012; Decru et al. 2016). Alignments were done using ClustalW and controlled by eye. Genetic distances were calculated between all haplotypes. The AIC identified $\mathrm{HKY}+\mathrm{G}$ as the best fitting model. As this model was not implemented in MEGA, the second best fit, TN93 + G, was employed.

Data were explored using principal component analysis (PCA) performed on the covariance matrix of the log-transformed measurements and on the correlation matrix of the meristics separately. Separate PCAs were done on the measurements with and without the two dorsal-fin ray lengths. For the former, 15 specimens with severely damaged dorsal fins were excluded. Missing values were handled by mean value imputation. The first principal component of the PCA on the log-transformed measurements was interpreted as a variable describing size (Zelditch et al. 2004). Therefore, the results of the PCA on the log-transformed measurements were visualised on scatterplots of the second versus the third principal component. Additionally, a canonical variates analysis (CVA) was performed for each of the three data sets. These were restricted to $L$. lineatus and the three populations of $L$. altivelis. A confusion matrix was calculated in which the 
true assignments of the specimens were compared with the assignments predicted by the CVA. The two aberrant lower Congo specimens (MRAC 47534-35), for which Tshibwabwa \& Teugels (1995) questioned the collection locality, were treated as mystery specimens: they were excluded from the analyses, but values for the $\mathrm{CV}$ were calculated in order to determine the group assignments. Differences in relative measurements and meristics were tested using pairwise Mann-Whitney U-tests, which were performed on sets of similar size class specimens (SL $P>0.1$ ). In order to reduce the number of pairwise comparisons, only biologically and systematically relevant comparisons were made. Finally, the allometric coefficients, $\mathrm{k}$, of the dorsal-fin ray lengths were calculated versus SL and versus each other. The coefficients were taken from the equation $\log (X)=\mathrm{k} \cdot \log (Y)+a$ (Huxley 1932), where $X$ is one of the two dorsal-fin ray lengths and $Y$ either SL or the other fin ray length. Estimates were performed by bivariate linear regression using ordinary least squares (OLS) and probabilities that these differed from isometry $(k=1)$ were calculated. Normality of residuals was verified using Shapiro-Wilk tests. As the use of regression to estimate allometric coefficients was criticised by Klingenberg (1996), coefficients were also calculated as relative factor loadings of a PCA. Sequential Bonferroni correction was used for the total number of tests. Statistical analyses were performed using Past (Hammer et al. 2001) and R (R Development Core Team 2008). Sequence data were analysed in MEGA v. 6 and visualised in a neighbor-joining tree and in a TCS haplotype network produced in MEGA v.6 (Tamura et al. 2013) and Popart (Leigh \& Bryant 2015), respectively.

\section{Results}

\section{Meristics}

Three meristic characters, the numbers of simple rays in the pectoral, pelvic and anal fins, were constant and were omitted from all analyses. A first PCA was performed on the remaining 15 meristics (Table S5). In the scatterplot of the first two principal components, four groups were identified (Fig. 1). The first group, with high values for the first and second PC, contained the three L. rosae specimens. The second, with intermediate values for both axes, contained L. mesops and L. sp. 'Ruaha'. The L. lineatus specimens formed a third group. The fourth, which showed some overlap with the previous, contained all L. altivelis specimens. In this group, specimens from the Congo and the Zambezi basins could not be separated, although the three specimens from the Lower Shire stood out by their higher value for PC1. No further geographical variation in meristics was discovered between the different populations of L. lineatus or L. altivelis, neither in this analysis, nor in subsequent analyses restricted to subsets of the data (not shown). All scale counts and, to a lesser extent, the numbers of branched dorsal- and anal-fin rays had positive contributions to the first PC. The number of branched dorsal rays was the most important contributor to PC2. A CVA was performed on the same data set for L. lineatus and the three populations of L. altivelis (Fig. S2, Tables S5, S6). The first $\mathrm{CV}$, which separated L. lineatus from L. altivelis, explained $86 \%$ of the variation. Although CV2 could separate Zambezi from Congo L. altivelis, values for specimens from the Bangweulu-Mweru ecoregion overlapped with both populations. No separation was obtained by CV3. The confusion matrix revealed that the CVA assigned all L. lineatus specimens correctly. Although all but one of the L. altivelis specimens were assigned to the correct species, only between 68 and $87 \%$ were placed in the correct population. A summary of the meristics of the different species and populations is presented in Table S2.

Differences in meristics between the three populations of L. altivelis were tested using pairwise Mann-Whitney $U$ tests. These tests were also performed between $L$. lineatus and the Congo population of L. altivelis (Table S7). Four differences were found between these sympatric groups, three of which very highly significant $(P<0.001)$. Yet, only the number of branched dorsal-fin rays showed no overlap and could be used to separate the species (Table S2). Between the Congo and Bangweulu-Mweru populations of L. altivelis, two meristics differed significantly: the number of branched dorsal-fin rays and the number of vertebrae,

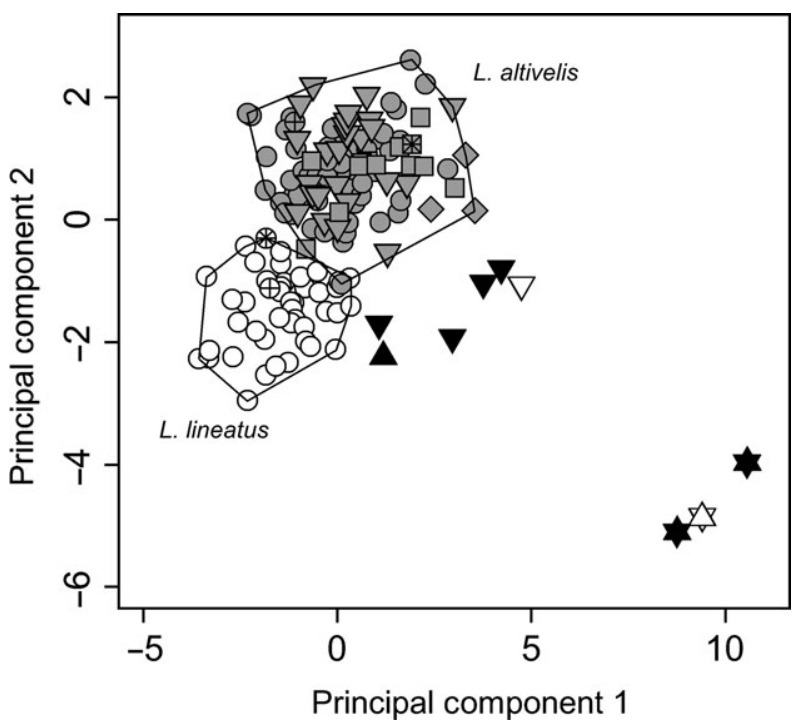

Fig. 1 PC2 vs. PC1 of the PCA on the correlation matrix of the meristics of 184 specimens, with: L. lineatus $(\bigcirc)$, L. altivelis Congo $(\bigcirc)$, L. altivelis Bangweulu-Mweru $(\nabla)$, L. altivelis Zambezi ( $\square$, including the Lower Shire: $\diamond)$, L. mesops $(\boldsymbol{\nabla})$, L. rosae $(\star)$ and $L$. sp. 'Ruaha' $(\boldsymbol{\Delta})$. Name-bearing specimens of L. lineatus $(\circledast)$, L. maleboensis $(\oplus)$, L. altivelis $(\mathbb{*})$, L. weeksii $(\oplus)$, L. mesops $(\nabla)$ and L. rosae ( $)$ are indicated separately. 
but values completely overlapped. Bangweulu-Mweru L. altivelis also differed in two meristics from their conspecifics from the Zambezi, whereas the latter differed in four from the Congo population. Values for all meristics, however, overlapped. Significance levels were, overall, larger in intra-, than in interspecific comparisons. Labeo mesops differed from $L$. lineatus and $L$. sp. 'Ruaha' by a higher number of lateral line scales (36-39 vs. 32-35) and from $L$. altivelis and $L$. rosae by a lower number of branched dorsal-fin rays (11 vs. $12-15)$. Labeo sp. 'Ruaha' had an even lower number of branched dorsal-fin rays (10). Labeo rosae differed from all other specimens by the high number of caudal peduncle and postdorsal scales (20 vs. $16-17$ and 1819 vs. 13-18).

\section{Measurements: body proportions}

A PCA was performed on the covariance matrix of the 19 measurements that did not include the measurements taken on the dorsal fin (Table S8). The second PC completely separated $L$. lineatus, which had positive values for this axis, from all other specimens (Fig. 2A). This component was positively correlated with measurements that indicate a wider head and negatively correlated with the length of the dorsal-fin base. The third PC allowed for an incomplete separation of three groups that had mainly negative values for PC2. The four L. mesops specimens were somewhat separated on the positive side of PC3. The Zambezi population of L. altivelis was found on the negative side of this axis, although there was a considerable overlap with their conspecifics from the Congo basin. This overlap was mainly caused by the specimens from the Lower Shire River. All L. altivelis specimens from the Congo basin had intermediate values for PC3, as did the L. rosae and the L. sp. 'Ruaha' specimens. The variables with the highest absolute contributions to PC3 were the caudal peduncle length, on the positive side, and the length of the anal-fin base, on the negative side. None of the PCs separated the Bangweulu-Mweru from the Congo populations of $L$. altivelis. Neither could any geographical variation within L. lineatus be observed. A CVA was performed on the same data set for L. lineatus and the three populations of $L$. altivelis (Fig. S3; Tables S6, S8). The first CV, which explained $75 \%$ of the variation, almost separated L. lineatus from $L$. altivelis. The second CV incompletely separated the Zambezi from the Congo and the Bangweulu-Mweru L. altivelis, whereas the last CV failed to distinguish between the latter two populations. The confusion table showed that body proportions can be used to correctly identify almost all L. lineatus and all L. altivelis specimens to the species level. Within L.altivelis, between 69 and $93 \%$ of the specimens were assigned to the correct population.
Measurements (as percentages) were compared between the same groups as in the analysis of the meristics (Table S9). Between sympatric L. altivelis and L. lineatus, seven measurements differed significantly, six of which even at the 0.001 level. As with the meristics, fewer significant differences were found in comparisons between the Bangweulu-Mweru population and the Zambezi and Congo populations of L.altivelis, than in comparisons between the latter two (1 vs. 2, respectively). In intraspecific comparisons of L. altivelis, all significance levels were higher than $0.001 \%$. Despite the differences revealed by the Mann-Whitney U-tests, all measurements overlapped between L. lineatus and L. altivelis (Table S3). However, when interorbital (IOrbW) and interoccipital (IOccW) widths were expressed as percentages of SL (instead of $\mathrm{HL}$ ), it was possible to differentiate large (SL > 100) specimens of L. lineatus from L. altivelis $(8.0-10.1 \%$ and $13.3-16.1 \%$ in L. lineatus vs. $4.9-7.8 \%$ and $10.2-13.0 \%$ in L. altivelis for IOrbW and IOccW, respectively). Also in smaller specimens, these variables are still useful identification criteria as they showed very little overlap (7.4-10.3\% and $12.6-16.5 \%$ in L. lineatus vs. $4.9-8.0 \%$ and $6.9-13.0 \%$ in L. altivelis). Percentages of the measurements that differed between the three L. altivelis populations all overlapped. For the other taxa, only few specimens were available for study and intraspecific variation could not be investigated. Labeo mesops differed from all other species by its narrower caudal peduncle (11.5-12.8\% vs. $12.8-22.5 \%)$ except for the Zambezi population of L. altivelis. However, L. mesops differed from the latter group by its shorter dorsal- and anal-fin bases (18.1-20.0\% and $6.2-7.8 \%$ vs. $20.7-29.4 \%$ and $8.1-10.5 \%$ for $\mathrm{DFB}$ and $\mathrm{AFB}$, respectively). No measurement separated $L$. rosae from $L$. lineatus or L. altivelis.

\section{Dorsal-fin shape}

A subsequent PCA was performed including the two dorsal-fin measurements (LUDR, 5th BDR) (Table S10). These additional variables had the highest absolute contributions to both PC2 and PC3. For PC2, both lengths had a negative contribution whereas, for PC3, 5th BDR was the variable with the most important negative contribution and LUDR that with the most important positive contribution. Therefore, PC2 can be interpreted as differentiating between small (positive) and large (negative) dorsal fins, while PC3 discriminates between concave (positive) and convex (negative) dorsal fins.

In a scatterplot of PC3 versus PC2, similar groups as those found in the previous analysis were identified (Fig. 2B). Some differences were, however, eminent. Foremost, the Zambezi population of L. altivelis was separated from that of the Congo. Specimens from the Bangweulu- 

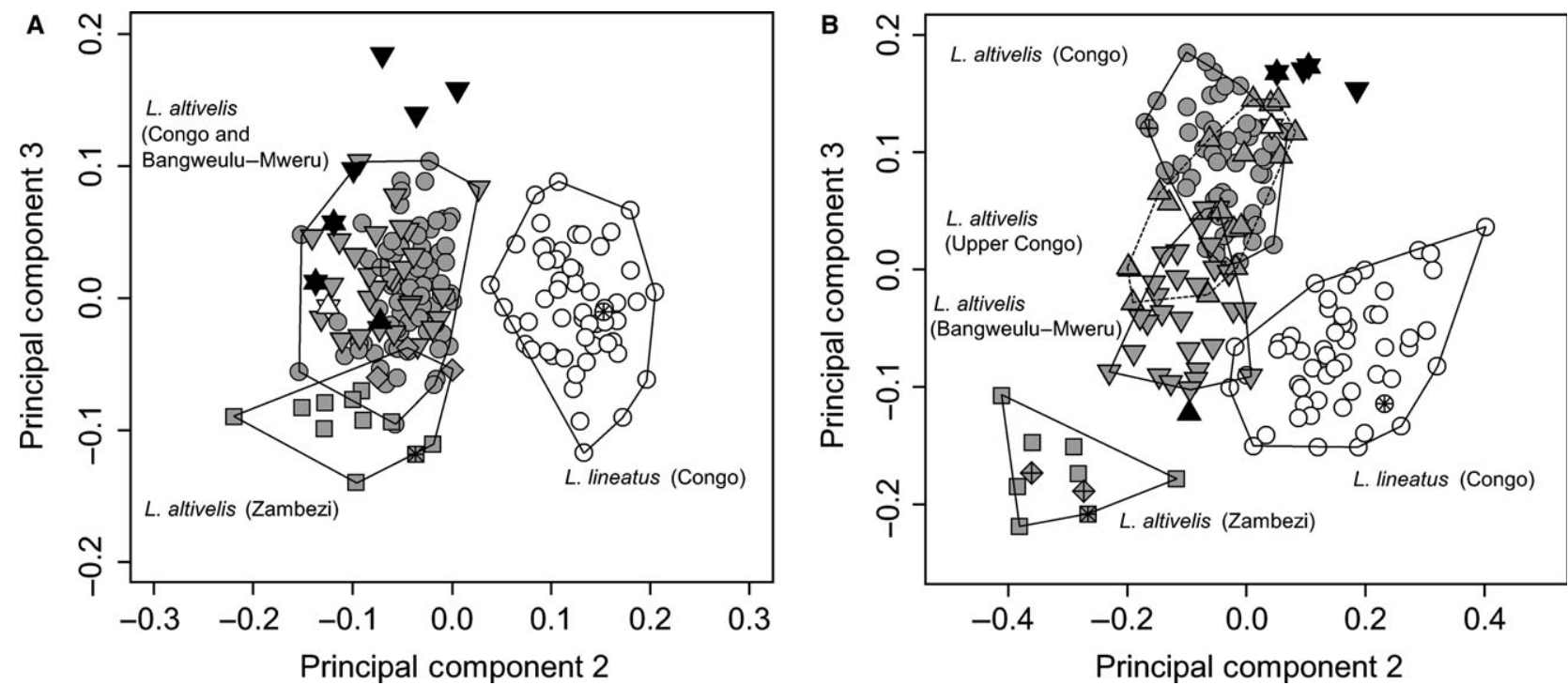

Fig. 2 PC3 vs. PC2 of the PCA on the covariance matrix of the log-transformed measurements on 183 resp. 168 specimens without (A) and with (B) the two measurements of dorsal-fin rays, the inclusion of which revealed geographical variation in L. altivelis, with L. lineatus $(\bigcirc)$, L. altivelis Congo $(\bigcirc)$, L. altivelis Bangweulu-Mweru $(\nabla)$, L. altivelis Zambezi $(\square$, including the Lower Shire: $\diamond)$, L. mesops $(\nabla)$, L. rosae $(\star)$ and L. sp. 'Ruaha' $(\mathbf{\Delta})$. Name-bearing specimens of L. lineatus $(\circledast)$, L. maleboensis $(\oplus)$, L. altivelis $(\mathbb{*})$, L. weeksii $(\oplus)$ and L. rosae $(\star)$ are indicated separately. In (B) values for L. altivelis from the upper Congo $(\Delta)$ and for the two aberrant Lower Congo L. altivelis $(\diamond)$ are visualised separately.

Mweru population, however, were intermediate between both. Although values for PC3 from the BangweuluMweru and from the Congo populations largely overlapped, this overlap was mainly caused by specimens from the Lualaba (Upper Congo) basin, which is downstream from the Bangweulu-Mweru ecoregion. This geographical variation was not found in the previous analysis. Unexpectedly, two L. altivelis specimens from the Lower Congo (MRAC 47534-35) clustered with their conspecifics from the Zambezi, whereas all other Lower Congo L. altivelis grouped with those from the Middle and Upper Congo. Tshibwabwa \& Teugels (1995) and Tshibwabwa (1997) listed these two specimens as $L$. altivelis, whereas they identified all other Lower and Middle Congo specimens as $L$. weeksii. Finally, $L$. rosae clustered with $L$. mesops, whereas L. sp. 'Ruaha' fell within L. altivelis. A CVA was performed on the same data set, but restricted to L. lineatus and the three L. altivelis populations (Fig. S4; Table S6, S10). The first CV again incompletely separated L. lineatus from L. altivelis. This axis, however, explained less variation as in the previous analysis (56 vs. $75 \%$ ). The second CV separated Congo from Zambezi L. altivelis. The BangweuluMweru population, which in the previous analysis completely overlapped with that from the Congo, was now intermediate between both populations. The third CV did not provide a better separation between any of the L. altivelis populations than CV2. In this analysis, with the dorsal-fin lengths included, the success rate of the reassignments increased from 98 to $100 \%$ for the species level and from $69-93$ to $79-93 \%$ for the three L. altivelis populations. Here, the 'aberrant' Lower Congo specimens were assigned to the Zambezi population.

The differences in relative fin lengths were tested between the L.altivelis populations and L. lineatus using Mann-Whitney $U$-tests (Table S11). The two 'aberrant' Lower Congo specimens were omitted from these tests. In order to compare specimens of comparable size, only specimens larger than $80 \mathrm{~mm} \mathrm{SL}$ were used. As no small Zambezian L. altivelis specimens $(\mathrm{SL}<134.5 \mathrm{~mm})$ were available, only specimens larger than $120 \mathrm{~mm}$ SL were used in the comparisons with this population. These tests revealed that the last unbranched dorsal-fin ray was significantly shorter in L. lineatus than in L. altivelis from all populations. The length of the fifth branched dorsal-fin ray did not differ between $L$. lineatus and sympatric $L$. altivelis from the Congo population. Yet, their 5th branched dorsal-fin rays were significantly shorter than in L. altivelis specimens from the Bangweulu-Mweru population, which had shorter fins ray than Zambezi specimens. Finally, the ratio of the fifth branched to the last unbranched dorsal ray, which denotes the shape of the fin, was significantly smaller in L. altivelis from the Congo, than in specimens from all other groups. Between the other groups, no significant difference in shape was observed. 


\section{Allometric growth of the dorsal fin}

The occurrence of allometry in the measurements of the dorsal-fin rays was investigated (Table 1) in L. lineatus and the different populations of L. altivelis. Allometric coefficients, $k$, were calculated using both regression and PCA. In all but one of the cases, these differed less than the standard error of the first estimate, indicating that both methods yield similar results (Zelditch et al. 2004). Probabilities that $\mathrm{k}$ differed from isometry $(k=1)$ were calculated (Table 1). As no small (<134.5 mm SL) Zambezian L. altivelis specimens with undamaged fins were available, this population was excluded from the calculations, as were the two 'aberrant' Lower Congo specimens.

For L. lineatus, the length of the last unbranched dorsalfin ray was negatively allometric $(k<1)$ to SL, whereas a positive allometry $(k>1)$ was encountered for $L$. altivelis from the Congo population. For L. altivelis from the Bangweulu-Mweru population, the growth of this fin ray did not differ from isometry with regard to SL $(k=1)$. For the fifth branched dorsal ray, the allometric coefficient was positive in all three groups although, after Bonferroni correction, the difference from isometry was not significant in L. lineatus and L. altivelis from the Congo population. Finally, the allometric coefficient of the length of the fifth branched dorsal ray versus that of the last unbranched dorsal ray, which describes the shape of the fin, was positive in L. lineatus and L. altivelis from the Bangweulu-Mweru and negative in L. altivelis from the Congo population. Although allometric coefficients could not be calculated for L. altivelis from the Zambezi population, scatterplots (Fig. S5) suggest that all three ratios examined were also positive for this group.

To summarise, in three of the groups: L. lineatus, L. altivelis from the Bangweulu-Mweru and from the Zambezi population, the convexity of the dorsal fin increases during growth. The mechanism in which this is achieved is, however, different. In the first group, a (slightly) convex dorsal fin is obtained due to the reduced growth of the anterior dorsal-fin rays (measured here as LUDR). In the second group, the dorsal fin becomes convex as a result of the relative faster growth of the middle dorsal-fin rays (measured here as 5th BDR). In the third group, all fin rays seem to have a positive allometric growth trajectory; yet as the middle dorsal-fin rays seem to grow faster than the anterior rays, a highly convex, sail-like fin develops in large individuals. Hence, large L. lineatus specimens have small convex fins, large Zambezian L. altivelis have large convex fins, whereas L. altivelis specimens from the Bangweulu-Mweru ecoregion have convex dorsal fins of intermediate size. In L. altivelis from the Congo population, the dorsal fin becomes concave due to the accelerated growth of the anterior fin rays, resulting in a large, sickle-shaped dorsal fin in large specimens (Fig. 3).

Although almost all of the percentages of fin lengths overlapped for small specimens, the allometric differences enabled the use of relative fin ray lengths as identification tools in specimens of larger size (Table S4). For specimens larger than $120 \mathrm{~mm} \mathrm{SL}$, the relative length of the last unbranched dorsal ray versus SL and the length of the fifth branched relative to the last unbranched dorsal-fin ray allowed for a complete separation of L. lineatus from sympatric L. altivelis $(16.2-26.7 \%$ and $67.0-116.2 \%$ in L. lineatus vs. $27.6-50.9 \%$ and $31.9-66.9 \%$ in Congolese L. altivelis). The relative length of the fifth dorsal-fin ray versus SL also separated Zambezian L. altivelis from all other groups $(34.3-50.8 \%$ in Zambezian L. altivelis vs. $13.2-32.1 \%$ for the other groups), with the exception of the two 'aberrant' specimens from the Lower Congo.

\section{DNA barcoding}

The new L. altivelis sequences were compared with all available COI sequences from African Labeo species with papillate lips on GenBank (Appendix S1). In addition to those of L. altivelis and L. lineatus, sequences of Labeo horie Heckel, 1847, Labeo senegalensis Valenciennes, 1842 and Labeo vulgaris Heckel, 1847 were also available. For the latter three species, identifications could not be verified. Although three sequences (GI: 313491860, 300876300 and

Table 1 Allometric coefficients $(k)$ of ratios of dorsal-fin ray lengths, estimated using bivariate regression (B) and PCA (P), the $P$ value for $k=1$ is calculated for $k(\mathrm{~B})$; LUDR: last unbranched dorsal-fin ray; 5th BDR: fifth branched dorsal-fin ray. Specimens of all sizes belonging to L. lineatus $(N=52)$, L. altivelis from the Congo basin excluding Bangweulu-Mweru $(\mathrm{Co}, N=72)$ and L. altivelis from BangweuluMweru (BM, $N=28)$ were used. By lack of small specimens, L. altivelis from the Zambezi was not included

\begin{tabular}{|c|c|c|c|c|c|c|c|c|c|}
\hline & \multicolumn{3}{|l|}{ LUDR vs. SL } & \multicolumn{3}{|c|}{ 5th BDR vs. SL } & \multicolumn{3}{|c|}{ 5th BDR vs. LUDR } \\
\hline & $k(\mathrm{~B})$ & $k(\mathrm{P})$ & $P(k=1)$ & $k(\mathrm{~B})$ & $k(\mathrm{P})$ & $P(k=1)$ & $k(\mathrm{~B})$ & $k(\mathrm{P})$ & $P(k=1)$ \\
\hline L. lineatus & $0.83 \pm 0.03$ & 0.83 & $1.5110^{-8 * * *}$ & $1.09 \pm 0.04$ & 1.10 & $1.5010^{-2}$ & $1.29 \pm 0.04$ & 1.32 & $1.9410^{-9 * * *}$ \\
\hline L. altivelis (Co) & $1.27 \pm 0.06$ & 1.29 & $5.0910^{-5 * *}$ & $1.15 \pm 0.05$ & 1.18 & $6.7910^{-3}$ & $0.83 \pm 0.04$ & 0.91 & $2.3410^{-4 *}$ \\
\hline L. altivelis (BM) & $1.05 \pm 0.05$ & 1.06 & 0.35 & $1.40 \pm 0.06$ & 1.41 & $1.2610^{-7 * * *}$ & $1.28 \pm 0.06$ & 1.33 & $1.3910^{-4 *}$ \\
\hline
\end{tabular}

$*, * *$ and $* * *$ denote significance on the $0.05,0.01$ and 0.001 level (after sequential Bonferroni correction). 


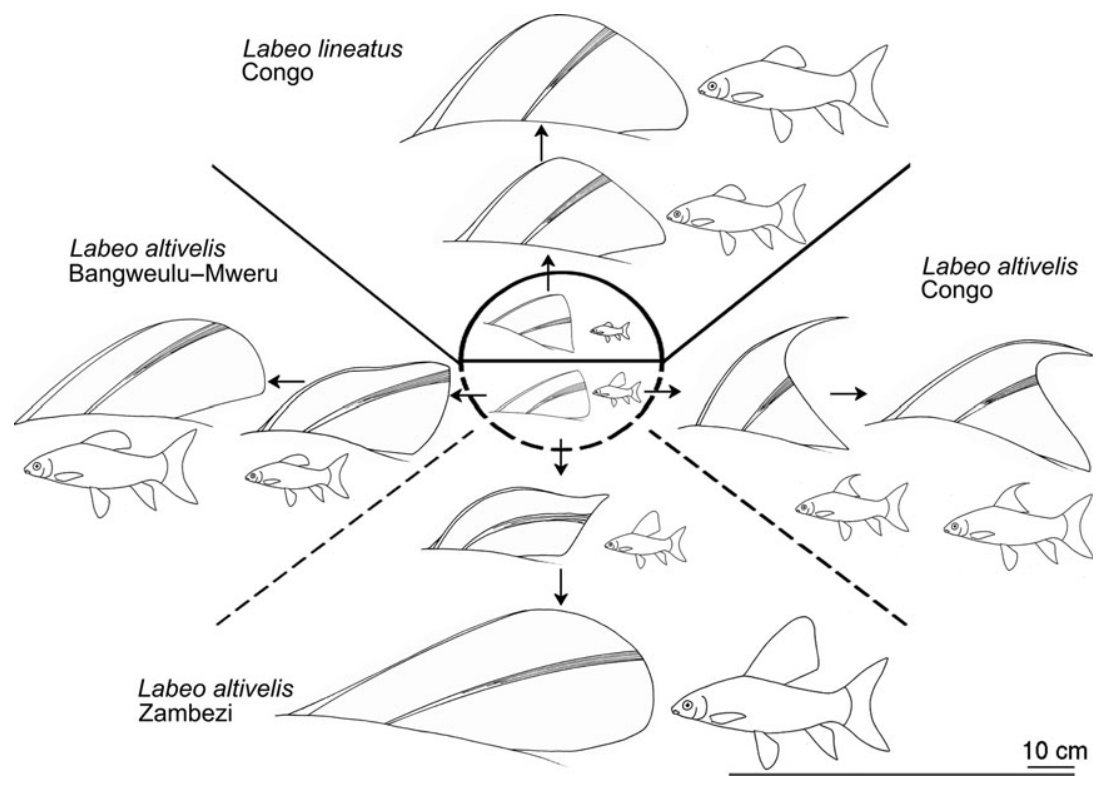

Fig. 3 Schematic overview of how differences in allometric growth produce differently shaped dorsal fins in L. lineatus and in the different L. altivelis populations: starting with a similarly shaped fin in juveniles (centre), L. lineatus (top) will have relatively small convex fins in adults; L. altivelis from the Congo basin (excluding Bangweulu-Mweru) (right) will develop relatively large sickle-shaped fins; L. altivelis from the Zambezi population (bottom) will obtain large highly convex fins and L. altivelis from the Bangweulu-Mweru ecoregion (left) develop convex fins of intermediate size. Pictograms of fishes represent the size of the specimens of which the fin was drawn, the scale bar represents the scale at which fish pictograms (black) and fins (grey) were drawn, fins in the circle are drawn at double scale, and the two fin rays measured (last unbranched and 5th branched dorsal ray) are shown in detail.

3008876296) were listed under L. lineatus in GenBank, these corresponded to voucher specimens of Labeo greenii Boulenger, 1902 according to Lowenstein et al. (2011) and were not included in the analysis. Genetic distances are summarised in Table S12 and a neighbor-joining tree and a haplotype network are presented in Fig. S6. Except for the comparison between L. horie and L. senegalensis $(0.2 \%)$, which falls outside of the scope of this study, interspecific differences were always larger than $1.6 \%$, whereas intraspecific differences were $1 \%$ at most. The highest intraspecific distance was observed between L. altivelis sequences originating from the Lower Congo and the Lower Zambezi. Labeo altivelis from the Bangweulu-Mweru ecoregion, which was also morphologically intermediate, had genetically equidistant sequences from both. Within L. lineatus, sequence diversity was always lower than $0.3 \%$. This species has, however, a smaller distribution range and its genetic differentiation is comparable to that seen in the Congo population of $L$. altivelis.

\section{Colour pattern and lip structure}

A clear precaudal spot was present on all preserved L. lineatus specimens smaller than $165 \mathrm{~mm} \mathrm{SL}$, including the holotype of L. maleboensis $(70 \mathrm{~mm} \mathrm{SL})$. This spot was fainter on larger specimens and could no longer be observed on any of the largest specimens (>165 mm SL). On none of the specimens belonging to L. altivelis, L. mesops and $L$. rosae, such a spot was observed, regardless of the size of the specimen. A clear black spot was, however, visible on the $L$. sp. 'Ruaha' specimen, even though the specimen was already quite large $(161 \mathrm{~mm} \mathrm{SL})$. A close examination of the colour pattern showed that in all specimens examined, melanin pigments were present at the outer margin of the scales. These formed a series of lateral bands on the flanks. Photographs of life specimens from different parts of the Congo basin (Fig. S7) revealed that, in vivo, these bands and stripes were dark green to black on $L$. lineatus, whereas they were lighter green and never black on $L$. altivelis. On small $L$. lineatus specimens and on the specimen from the Ruaha River, some posterior scales on the caudal peduncle contain these pigments over their whole surface, creating the dark precaudal spot. Skelton (2001) also mentioned a precaudal dark spot on juvenile southern African L. altivelis and L. rosae. This was, however, not observed on any of the preserved Zambezian L. altivelis. Hence, at least in the Congo basin, the presence of a precaudal spot could be used to distinguish small L. lineatus $(<165 \mathrm{~mm} \mathrm{SL})$ from small L. altivelis.

Although all specimens had papillate lips, these papillae were arranged in oblique overlying rows in some large 
L. lineatus specimens. Hence, these papillae were positioned in a similar way as the plicae in Labeo specimens from the plicate groups. This similarity might have led Tshibwabwa (1997) to identify a paralectotype of L. lineatus together with six other large specimens as Labeo degeni Boulenger, 1920. As all these specimens had papillary lips and 11 dorsal-fin rays (versus plicate lips and 10 dorsal-fin rays in the L. degeni lectotype), they were re-identified as L. lineatus (Appendix S1).

\section{Discussion}

The results reaffirm the distinction between L. altivelis and L. lineatus. The holotype of L. maleboensis proved to be conspecific with L. lineatus, confirming earlier molecular results (Lowenstein et al. 2011). The identification of the two specimens from the Lufira River as L. rosae (Van Steenberge et al. 2014b) was also confirmed. The status of L. mesops as a Lake Malawi basin endemic (Snoeks 2004) was validated although, at least for meristic characters, this species had affinities with the unidentified specimen from the Ruaha River.

In Labeo systematics, much weight has traditionally been given to one conspicuous trait, the shape of the dorsal fin (Boulenger 1909; Reid 1985; Tshibwabwa 1997). Hence, it is no surprise that four groups potentially corresponding to four of the five nominal species previously listed from the Congo basin, L. lineatus, L. altivelis, L. weeksii and L. rosae, were retrieved in the PCA of the measurements, when dorsal-fin lengths were included (Fig. 2B). Previously, all L. altivelis specimens from the Congo basin were classified as L. weeksii except for most of the specimens from the Bangweulu-Mweru ecoregion and for two 'aberrant' Lower Congo specimens. When dorsal-fin measurements were included, both PCA and CVA separated these specimens from L. altivelis from the rest of the basin (Fig. 2B). Yet, without these measurements, this distinction could no longer be retrieved.

Labeo altivelis from the Bangweulu-Mweru ecoregion differed significantly in the same amount of measurements and counts (4) from specimens from the Congo as from those of the Zambezi population. Two times as many significant differences were found in the comparison between the Congo and the Zambezi populations. Specimens from the Bangweulu-Mweru ecoregion were also intermediate between both populations in the three CVAs. This was in agreement with the DNA barcoding results where the haplotypes of the Bangweulu-Mweru population were equidistant to those of the other populations. Yet, except for the shape of the dorsal fin, no character was found that could unambiguously separate any of the geographical units. Therefore, all evidence justifies the treatment of all three groups as belonging to the same widespread species and the synonymy of $L$. weeksii with $L$. altivelis. Redescriptions of L.altivelis, L. lineatus and L. rosae are given in Appendix S1.

The Lake Malawi endemic L. mesops was clearly distinct from all other species. Interestingly, in the analyses of both meristics and measurements, the specimens from the Lower Shire, which connects Lake Malawi with the Zambezi, were somewhat intermediate between L. altivelis and L. mesops. Possibly, hybridisation might have occurred between L. altivelis and L. mesops specimens that ended up downstream of the Lake's basin. Alternatively, L. altivelis from the Shire could represent the population of the parent species out of which L. mesops evolved in the geographically isolated Lake Malawi basin. A similar situation could explain the distributions of Serranocbromis robustus jallae (Boulenger, 1896), from the Zambezi and Congo basins and Serranocbromis robustus robustus (Günther, 1864), also a Lake Malawi endemic. Alternatively, the Lake's catchment could also have been colonised via the Bangweulu-Mweru ecoregion, as was shown for Pseudocrenilabrus philander (Weber, 1897) (Egger et al. 2015). The widespread catfish, Clarias gariepinus Burchell, 1822, which occurs in the Lake, also represents a parent species of a separate Malawi clade: the entire Bathyclarias Jackson, 1959 species flock (Agnèse \& Teugels 2001).

Labeo altivelis is absent from the Upper Zambezi, the Kafue and the Luangwa (Skelton 2001). The Labeo species with papillary lips from the Little Ruaha River, which drains into the Rufiji, belongs to a different species. Hence, L. altivelis has a large gap between its north-western (Congo) and south-eastern (Zambezi) distribution. Similar distributions are found in L. rosae, Enteromius motebensis (Steindachner, 1894) and Enteromius mattozi (Guimarães, 1894), which have even larger gaps in their distributions (Skelton 2001; Van Steenberge et al. 2014b). These disjoint distributions can be explained by previous connections between the Congo and the Zambezi systems (Moore \& Larkin 2001; Stankiewicz \& de Wit 2006), followed by local extinctions. This scenario was also put forward for the tigerfish, Hydrocynus vittatus Castelnau, 1861, for which the absence in the Kafue was interpreted as resulting from a period of local aridity (Cotterill \& de Wit 2011).

The shape of the dorsal fin contains a large amount of allometric and geographical variation in L. altivelis, whereas it is remarkably stable in L. lineatus (Fig. 3). Variation in dorsal-fin shape was already reported for L. altivelis populations from southern African river basins. Here, different river systems harbour populations with either concave or convex dorsal fins and the size of the dorsal fin is smaller 
in populations from river systems south of the Zambezi (Bell-Cross 1976). The difference in dorsal-fin shape between specimens from the Bangweulu-Mweru ecoregion and of those from the rest of the Congo basin was the reason why the former were previously identified as $L$. altivelis and the latter as $L$. weeksii. The Bangweulu-Mweru ecoregion forms an isolated part of the Congo basin (Scott 2005; Van Steenberge et al. 2014a). Therefore, the geographical variation in dorsal-fin shape in L. altivelis from the Congo (including Bangweulu-Mweru) is comparable to that reported from southern Africa. Two aberrant L. altivelis specimens from the Lower Congo also had highly convex dorsal fins. Yet, no additional characters were found in which they differed from conspecifics from this region. Unfortunately, the exact origin of these specimens is not known. Hence, it is uncertain whether they originate from an isolated part of the basin, or whether they were found in sympatry with $L$. altivelis specimens with concave dorsal fins. Yet, as they clearly belong to L. altivelis, there is no need to question the museum labels or to speculate that they might have been collected elsewhere (Tshibwabwa \& Teugels 1995).

The high degree of intra- and interspecific variation in dorsal-fin shape is produced by differential growth rates of different parts of the fin (Table 1). Although the proximate causes of this mechanism remain unknown, a genetic basis is at least partially involved as sympatric L. lineatus and L. altivelis obtain increasingly differently shaped dorsal fins during growth. Environmental influences could, however, also act on the development of this character. In L. altivelis, specimens from the cooler upper reaches of the Congo basin have similarly shaped fins as specimens from more southern basins. In the tropical rainforest, all specimens have a concave dorsal fin. This could explain the convex dorsal fins of the two aberrant Lower Congo L. altivelis as this area contains some regions with higher elevations and cooler climates.

To summarise, the high amount of geographical and allometric differences in the shape and size of the dorsal fin makes it an unsuitable character for species delineation in papillate Labeo. Yet, its conspicuous appearance does render it useful for rapid identification of sufficiently large (SL $>120 \mathrm{~mm}$ ) specimens. A similar conspicuous trait, the precaudal spot, is also of only limited value for delineation as it is never present in large specimens. Yet, its presence does allow us to distinguish small ( $\mathrm{SL}<165 \mathrm{~mm}$ ) L. lineatus from sympatric congeners. Only meristic characters could be used to distinguish L. altivelis, L. linatus and L. rosae unambiguously. Hence, the case of the papillate Labeo from the Congo basin illustrates that even when conspicuous traits that allow for easy identification are present, species delineations based solely on them could be erroneous.

\section{Acknowledgements}

This work was partially conducted during a FishBase and Fish Taxonomy visit to the RMCA (AC) and during a professional internship of the "Oceans and Lakes" master programme (LG). We thank T. Moelants (RMCA/KU Leuven) and G. Banyankimbona (University of Burundi) for collecting specimens and providing photographs, Sarah Tilkin (KU Leuven) for making gill raker counts, Miguel Parrent (RMCA) for collection management, Alain Reygel and Lore Nackaerts for providing figure 3, Frank Willems, the Kasanka trust and the Zambian Wildlife Authority (ZAWA) for facilitating fieldwork by MVS in Kasanka N.P. (Zambia) and Hedwig Ens, Céline Gillardin and Leonard Nkandu for assistance during fieldwork, R. Bills and Z. Adam (SAIAB), P. Bartsch, C. Lamour (ZMB), J. Maclaine (BMNH) and H. Wellendorf (NMW) for their hospitality during study visits of MVS and EV and for sending specimens. Results were presented at the 5th PAFFA conference in Bujumbura (Burundi) thanks to support of the All Cypriniformes Species Inventory (ACSI-2) project. MVS profited of a VLIR-UOS travel grant for fieldwork in Zambia. Study visits of $\mathrm{EV}$ to the ZMB were supported by Synthesis grants: DE-TAF-1802, April 2012 and DE-TAF-3590, April 2014.

\section{References}

Agnèse, J. F. \& Teugels, G. G. (2001). The Bathyclarias-Clarias species flock. A new model to understand rapid speciation in African Great Lakes. Comptes rendus de l'académie des sciences serie III, Sciences de la vie, 324, 683-688.

Bell-Cross, G. (1976). The Fishes of Rhodesia. Harare: Trustees of the National Museums and Monuments of Rhodesia.

Boulenger, G. A. (1903). List of the African species of the cyprinid genus Labeo, with a key to their identification. Annals and Magazine of Natural History (Zoology), 12, 355-362.

Boulenger, G. A. (1909). Catalogue of the Fresh-Water Fishes of Africa in the British Museum (Natural History). London: British Museum (Natural History).

Cotterill, F. P. D. \& de Wit, M. J. (2011). Geoecodynamics and the Kalahari epeirogeny: linking its genomic record, tree of life and palimpsest into a unified narrative of landscape evolution. South African Fournal of Geology, 114, 489-514.

Decru, E., Moelants, T., De Gelas, K., Vreven, E., Verheyen, E. \& Snoeks, J. (2016). Taxonomic challenges in freshwater fishes: a mismatch between morphology and DNA barcoding in fish of the north-eastern part of the Congo basin. Molecular Ecology Resources, 16, 342-352.

Egger, B., Klaefiger, Y., Indermaur, A., Koblmüller, S., Theis, A., Egger, S., Näf, T., Van Steenberge, M., Sturmbauer, C., Katongo, C. \& Salzburger, W. (2015). Phylogeographic and phenotypic assessment of a basal haplochromine cichlid fish from Lake Chila, Zambia. Hydrobiologia, 748, 171-184.

Hammer, Ø., Harper, D. A. T. \& Ryan, P. D. (2001). PAST: paleontological statistics software package for education and data analysis. Palaeontologia Electronica, 4, 9 pp. 
Huxley, J. S. (1932). Problems of Relative Growth. London: Methuen \& Co. Ltd.

Jubb, R. A. (1958). A preliminary report on the collections of freshwater fishes made by the Bernard Carp expeditions to the Caprivi Strip, 1949, the Lower Sabi River, 1950, and to Barotseland, 1952. Occasional Papers of the National Museum of Southern Rhodesia, 22B, 177-189.

Klingenberg, P. C. (1996). Multivariate allometry. In: L. F. Markus, M. Corti, A. Loy, G. J. P. Naylor \& D. E. Slice (Eds.) Advances in Morphometrics (pp. 23-49). New York: Plenum Press.

Leigh, J. W. \& Bryant, D. (2015). POPART: full-feature software for haplotype network construction. Methods in Ecology and Evolution, 6, 1110-1116.

Löbl, I. (2014). Overestimation of molecular and modelling methods and underestimation of traditional taxonomy leads to real problems in assessing and handling of the world's biodiversity. Zootaxa, 3768, 497-500.

Lowenstein, J. H., Osmundson, T. W., Becker, S., Hanner, R. \& Stiassny, M. L. J. (2011). Incorporating DNA barcodes into a multi-year inventory of the fishes of the hyperdiverse Lower Congo River, with a multi-gene performance assessment of the genus Labeo as a case study. Mitochondrial DNA, 21, 1-19.

Matthes, H. (1963). A comparative study of the feeding mechanisms of some African Cyprinidae (Pisces, Cypriniformes). Bijdragen tot de Dierkunde, 33, 1-35.

Mayr, E. (1982). The Growth of Biological Thought: Diversity, Evolution and Inheritance. Cambridge, MA: Harvard University Belknap Press.

Moore, A. E. \& Larkin, P. A. (2001). Drainage evolution in southcentral Africa since the breakup of Gondwana. South African Fournal of Geology, 104, 47.

$\mathrm{R}$ Development Core Team (2008) R: A Language and Environment for Statistical Computing. Vienna, Austria: R foundation for Statistical Computing.

Reid, G. M. (1985). A revision of the African species of Labeo (Pisces: Cyprinidae) and a re-definition of the genus. Theses Zoologicae, 6, 1-322.

Scott, L. (2005). Bangweulu-Mweru. In: M. L. Thieme, R. Abell, M. L. Stiassny, P. Skelton, B. Lehner, E. Dinerstein, G. G. Teugels, N. Burgess, A. K. Toham \& D. Olson (Eds) Freshwater Ecoregions of Africa and Madagascar: a Conservation Assessment (pp. 185-186). Washington, DC: Island Press.

Skelton, P. H. (2001). A Complete Guide to the Freshwater Fishes of Southern Africa. South Africa: Struik Publishers.

Skelton, P. H., Tweddle, D. \& Jackson, P. B. N. (1991). Cyprinids of Africa. In: I. J. Winfield \& J. S. Nelson (Eds) Cyprinid Fishes Systematics, Biology and Exploitation (pp. 211-263). London: Chapman \& Hall.

Snoeks, J. (2004). The non-cichlid fishes of the Lake Malawi system: a compilation. In: J. Snoeks (Ed) The Cichlid Diversity of Lake Malawi/Nyasa/Niassa: Identification, Distribution and Taxonomy (pp. 20-26). El Paso, Texas: Cichlid Press.

Stankiewicz, J. \& de Wit, M. J. (2006). A proposed drainage evolution model for Africa - did the Congo flow east? Fournal of African Earth Sciences, 44, 75-84.
Stiassny, M. \& Getahun, A. (2007). An overview of labeonin relationships and the phylogenic placement of the Afro-Asian genus Garra Hamilton, 1922 (Teleostei: Cyprinidae), with the description of five new species of Garra from Ethiopia, and a key to all African species. Zoological Fournal of the Linnean Society, 150, 41-83.

Tamura, K., Stecher, G., Peterson, D., Filipski, A. \& Kumar, S. (2013). MEGA6: molecular evolutionary genetics analysis version 6.0. Molecular Biology and Evolution, 30, 2725-2729.

Thys van den Audenaerde, D. F. E. (1987). Review: Reid, G. McG, 1985, A revision of the African species of Labeo (Pisces, Cyprinidae).. Revue de Zoologie Africaine, 100, 487-492.

Tshibwabwa, S. M. (1997). Systématic des espèces Africaines du genre Labeo (teleostei, cyprinidae) dans les regions ichthyogéographiques de Basse-Guinée et du Congo. Namur: Presses Universitaires de Namur.

Tshibwabwa, S. M. \& Teugels, G. G. (1995). Contribution to the systematic revision of the African cyprinid genus Labeo: species from the Lower Zaire river system. Fournal of Natural History, 29, 1543-1579.

Van Steenberge, M., Vreven, E. \& Snoeks, J. (2014a). The fishes of the Upper Luapula area (Congo basin): a fauna of mixed origin. Ichthyological Exploration of Freshwaters, 2(4), 329-345.

Van Steenberge, M., Gajdzik, L., Chilala, A., Snoeks, J. \& Vreven, E. (2014b). Labeo rosae (Cypriniformes: Cyprinidae) in the Congo basin: a relict distribution or a historical introduction? Fournal of Fish Biology, 85, 1733-1738.

Van Steenberge, M., Snoeks, J. \& Vreven, E. (2016). Lingering taxonomic confusion in Labeo (Cypriniformes, Cyprinidae): setting the records straight for the types of seven Congolese species. Acta Ichthyologica et piscatoria, 46, 1-8.

Worthington, E. B. (1933). The fishes (other than Cichlidae) of Lake Bangweulu and adjoining regions, including descriptions of three new species. Annals and Magazine of Natural History, 12, 34-52.

Yang, L., Arunachalam, M., Sado, T., Levin, B. A., Golubtsov, A. S., Freyhof, J., Friel, J. P., Chen, W. J., Hirt, M. V., Manickam, R., Agnew, M. K., Simons, A. M., Saitoh, K., Miya, M., Mayden, R. L. \& He, S. (2012). Molecular phylogeny of the cyrpinid tribe Labeonini (Teleostei: Cyrpinifomes). Molecular Phylogenetics and Evolution, 65, 362-379.

Zelditch, M. L., Swiderski, D. L, Sheets, H. D. \& Fink, W. L. (2004). Geometric Morphometrics for Biologists. London: Elsevier Academic Press.

\section{Supporting Information}

Additional Supporting Information may be found in the online version of this article:

Appendix S1. Species redescriptions \& Specimens studied.

Figs S1-S7. Additional figures.

Tables S1-S4. Character tables.

Tables S5-S12. Additional statistical analyses. 